\title{
PLANNING OF THE STRENGHT AND CONDITIONING PROGRAM TRAINING IN THE FIELD OF WRESTLING
}

\author{
Iliya Iliev \\ National Sports Academy "Vassil Levski", Sofia, Bulgaria
}

\begin{abstract}
Many scientific studies, pedagogical observations on training and competitive practice confirm the fact that the high level of development of the speed-power qualities of athletes, including wrestlers, is a major factor in the successful realization of the technical and tactical skills in the competitive conditions which is confirmed by many researches in the field of wrestling. The task of the study was to research and analysis the theoretical and practical problems of the methodology of the strength and conditioning program training in wrestling and apply a block periodization program for wrestlers design to create a periodized training program. The purpose of the study was to increase the efficiency of sports training by applying a specialized methodology to develop the basic motor skills of speed and explosive power. To assess the personality of the subjects studied were analyzed and compared literary sources as well as a pedagogical observation conducted. The results show that the experimentation of our work program for the improvement and preservation of speed-strength endurance significantly improved general and specific events motor (physical) characteristics of the athletes and their technical and tactical skills of hence the improvement of sports performance.
\end{abstract}

Key words: wrestling, periodization, strength and condition training programme

\section{INTRODUCTION}

Physical training is the basis for sportsmanship in modern wrestling. The degree of development of the various motor, physical qualities largely determines the possibilities and the volume of technical and tactical training, is inextricably linked with the motivation, self-confidence of the fighter and a number of personal qualities. The development of strength, speed, endurance, flexibility, agility of the fighter is put on a broad general sports training in order to develop and specialize gradually in the requirements of combat (Matveev, 1977). It is a long-term and complex process, in which many patterns are known. Some of them are of great importance for the fight as a sport (for example, the link between speed-power qualities and strength endurance in preparation). In others, the patterns are not so constant, but also depend on the level of development of other physical qualities, the goals of sports training and the design of the classes (Iliev, 2015).

According to Leipold, 2010 only if there is a perfect planning of the training the wrestler can effect optimal performance at the main competition. Many scientific studies, pedagogical observations on training and competitive practice confirm the fact that the high level of development of the speed-power qualities of athletes, including wrestlers, is a major factor in the successful realization of the technical and tactical skills in the competitive conditions confirmed by many researches in the field of wrestling (Bagaev, 1998; Igumenov, Akopyan, Mamiashvili and Osotov, 1987; Petrov, 1978; Shakhmuradov and Sukhanov, 1997; Stanchev, 2015). While strength and conditioning programs bring about significant improvements in strength, eventually physical adaptations and psychological adjustments will occur less frequently, and the athlete will experience performance plateaus or decrements. There may also be an increased risk of injury and other symptoms associated with overtraining (Baechle, Earle, 2008).

Aim of the study of the study was to increase the efficiency of sports training by applying a specialized methodology to develop the basic motor skills of speed and explosive power and optimaly performance in the most important competition of the year that prepares the wrestlers to peak at the right time such as National Championship, European Championships and World Championships. To assess the personality of the 
subjects studied were analyzed and compared literary sources as well as a pedagogical observation conducted almost throughout the whole study period. The main purpose in the preparation period was to increase overall strength and aerobic endurance. During the Special Preparation Period was to improve the physical and functional capabilities of the wrestler or competitor, transforming the overall strength and endurance into a special one.

\section{METHODOLOGY}

It has been used a plan program of a set of physical exercises (Table 1) for highly qualified wrestlers (participants of 16 persons; age 22,45 $\pm 3,7$; experience 8,54 years; $65 \pm 22 \mathrm{~kg}$ ). The training methods included disaggregated, comprehensive, competitive. The main exercises were with a partner, as well as some aids with Dummy Throws, Elastics bands and Bulgarian bag patented and invented by Ivan Ivanov. In most cases, the repetitions in Table 1 refers to the use of the selected exercises for one training session.

Depending on the purpose of the training activity, some of the exercises were applied at the end of the preparatory part and the beginning of the main part, as well as additional work after technical and tactical improvement.

Table 1. Periodization training program

\begin{tabular}{|c|c|c|c|c|c|c|c|c|c|}
\hline $\begin{array}{c}\text { Month } \rightarrow \\
\text { Exercises } \downarrow\end{array}$ & Oct & Nov & Dec & Jan & Feb & Mar & Apr & May & June \\
\hline $\begin{array}{l}\text { Bent Over Barbell Row - } \\
\text { Standard }\end{array}$ & $\begin{array}{c}4 \times 8 \\
70 \% \text { от } \\
\max \end{array}$ & $\begin{array}{c}1-8 \times 8 \\
70-90 \% \\
\max \end{array}$ & $\begin{array}{c}1-6 \times 8 \\
70 \% \\
\max \\
\end{array}$ & & & $\begin{array}{l}4 \times 8 \\
70 \% \\
\max \end{array}$ & $\begin{array}{c}1-8 \times 8 \\
70-90 \% \\
\max \end{array}$ & & \\
\hline $\begin{array}{l}\text { Imitation version } \\
\text { of Bent Over Barbell Row } \\
\text { with the help } \\
\text { of Elastic bands. }\end{array}$ & $4 \times 12$ & $4 \times 12$ & $6 \times 14$ & $8 \times 10$ & $6 \times 10$ & $4 \times 12$ & $4 \times 12$ & $6 \times 14$ & $6 \times 10$ \\
\hline $\begin{array}{l}\text { Bent Over Barbell Row }+ \\
\text { one repeat } \\
\text { with a partner }\end{array}$ & $\begin{array}{c}4 \times 6 \\
65-70 \% \\
\max \\
\end{array}$ & $\begin{array}{c}4 \times 6 \\
65-70 \% \\
\max \\
\end{array}$ & $\begin{array}{c}2 \times 6 \\
65-70 \% \\
\max \\
\end{array}$ & $\begin{array}{l}2 \times 4 \\
60 \% \\
\max \\
\end{array}$ & & $\begin{array}{c}4 \times 6 \\
65-70 \% \\
\max \end{array}$ & $\begin{array}{c}4 \times 6 \\
65-70 \% \\
\max \\
\end{array}$ & $\begin{array}{c}2 \times 665- \\
70 \% \\
\max \\
\end{array}$ & $\begin{array}{l}2 \times 4 \\
60 \% \\
\max \\
\end{array}$ \\
\hline $\begin{array}{l}\text { Complex of squats with } \\
\text { Bulgarian bag }\end{array}$ & $10 \times 10$ & $10 \times 12$ & $10 \times 14$ & $6 \times 10$ & $4 \times 10$ & $10 \times 10$ & $10 \times 12$ & $10 \times 14$ & $4 \times 10$ \\
\hline $\begin{array}{l}\text { Pull up an upper-body with } \\
\text { reducing the weight of the } \\
\text { wrestler }\end{array}$ & $4 \times 6$ & $4 \times 8$ & $4 \times 10$ & $6 \times 10$ & $4 \times 8$ & $4 \times 8$ & $4 \times 10$ & $6 \times 10$ & $4 \times 8$ \\
\hline Push-ups with dumbbells & $4 \times 10$ & $4 \times 12$ & $4 \times 14$ & $4 \times 15$ & & $4 \times 10$ & $4 \times 14$ & $4 \times 16$ & $4 \times 20$ \\
\hline Buckets exercises & $4 \times 8$ & $4 \times 10$ & $4 \times 12$ & $4 \times 12$ & $4 \times 8$ & $4 \times 8$ & $4 \times 10$ & $4 \times 16$ & $4 \times 10$ \\
\hline $\begin{array}{l}\text { Circular workout training } \\
\text { with elastic bands }\end{array}$ & & & $\begin{array}{c}30 \\
\min .\end{array}$ & $\begin{array}{c}40 \\
\min .\end{array}$ & $\begin{array}{c}30 \\
\min \\
\end{array}$ & & $\begin{array}{c}30 \\
\min .\end{array}$ & $\begin{array}{c}40 \\
\min \\
\end{array}$ & $\begin{array}{c}30 \\
\min \end{array}$ \\
\hline $30 \mathrm{~m}$ sprint running & $\begin{array}{c}2 \\
\text { times }\end{array}$ & $\begin{array}{c}2 \\
\text { times }\end{array}$ & $\begin{array}{c}4 \\
\text { times }\end{array}$ & $\begin{array}{c}6 \\
\text { times }\end{array}$ & $\begin{array}{c}6 \\
\text { times }\end{array}$ & $\begin{array}{l}2 \\
\text { times }\end{array}$ & $\begin{array}{c}4 \\
\text { times }\end{array}$ & $\begin{array}{c}6 \\
\text { times }\end{array}$ & $\begin{array}{c}6 \\
\text { times }\end{array}$ \\
\hline Throwing Dummies & $2 \times 4$ & $2 \times 6$ & $2 \times 8$ & $2 \times 10$ & $4 \times 10$ & $2 \times 4$ & $2 \times 6$ & $4 \times 8$ & $4 \times 10$ \\
\hline Long jump & $2 \times 4$ & $2 \times 6$ & $2 \times 8$ & $2 \times 10$ & $1 \times 10$ & $2 \times 4$ & $2 \times 6$ & $2 \times 10$ & $1 \times 10$ \\
\hline $\begin{array}{l}\text { Throwing } \\
\text { a medical ball }\end{array}$ & $2 \times 4$ & $2 \times 4$ & $2 \times 4$ & $2 \times 6$ & $2 \times 6$ & $2 \times 4$ & $2 \times 6$ & $2 \times 6$ & $2 \times 6$ \\
\hline
\end{tabular}

\section{RESULTS}

To measure the dynamics of the development of the results, there had been taken three measurements (respectively, study one was done at the beginning of the preparation period; study two was done at the end of the training period and study three at the beginning of the competition period. Table 2 shows the dynamics of changing in one examined person (age 22, height $171 \mathrm{sm}$., $57 \mathrm{~kg}$.) in seven different sports pedagogical tests. 
Table 2. Dynamics of the parameters

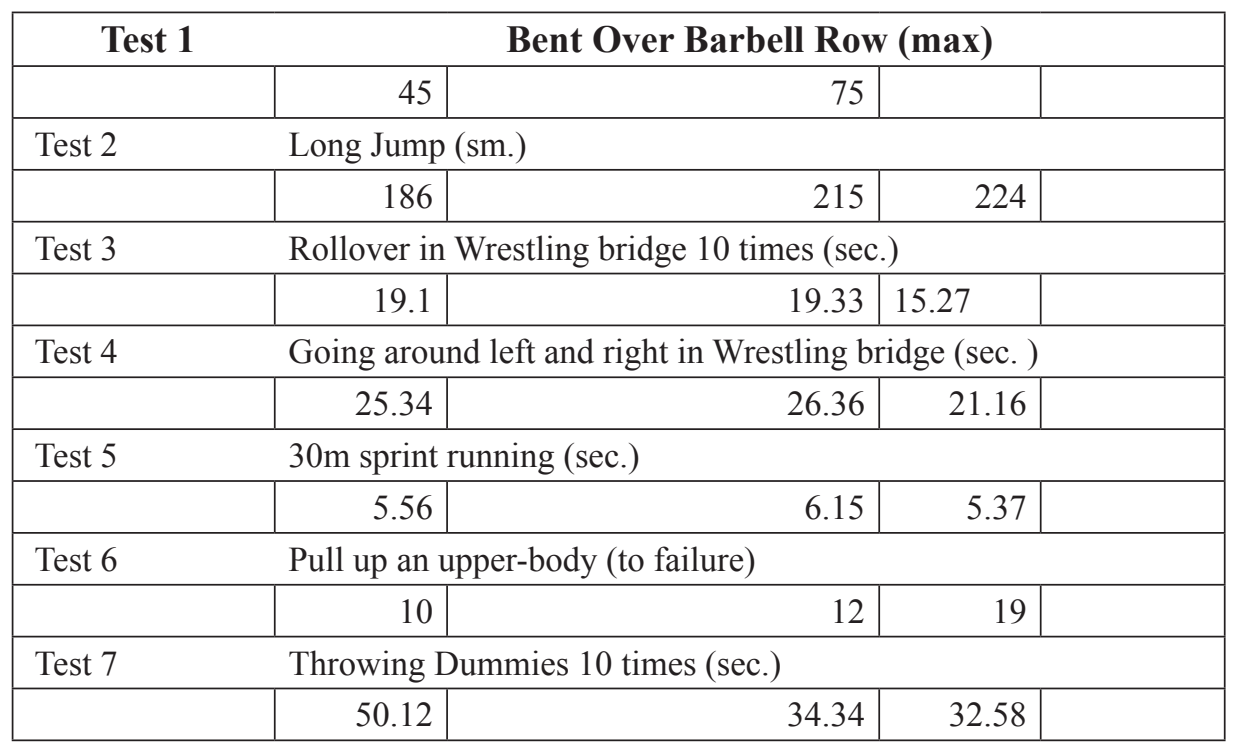

The dynamics of the development of maximum force can be traced in test 1. From the first study or the beginning of the general preparation period and at the end of the preparatory period, the difference is $30 \mathrm{~kg}$, which is a well done job in a six-week mesocycle on our proposed work program.

The result of a "long jump" from test 2 shows a large increase in the averages between the first research $(186 \mathrm{sm}$.$) and third research (224 \mathrm{sm}$.) and a slight increase in the values in the second study $(215 \mathrm{sm}$.).

In the next exercise "Rollover in Wrestling bridge - 10 times" the trend of change is more clear in the third part of the training program (19.1 sec. $<19.33 \mathrm{sec} .>15.27 \mathrm{sec}$.)- during the competitive phase.

In the exercise "Going around left and right in Wrestling bridge", (Test 4), the results are similar in dynamics to the exercise "Rollover in Wrestling bridge". We could relate the dynamics of change to the increase in specific strength power during the annual training cycle in the competitive phase, which respectively improves the time to perform these exercises. It can be seen that the running time decreases over the course of the annual training cycle as the speed of change is higher in the pre-competitive phase as it is a specific wrestling exercise to the development of specific workloads and technical skills.

$30 \mathrm{~m}$ sprint running test shows better values in the pre-competitive period.
The Pull up an upper-body test shows a large increase between study one (10 times) and study three (19 times). The tendency in the program we have developed here was to increase strength endurance from the beginning of the training process to the end of the preparatory phase of the annual training cycle and to retain thereafter during the pre-competitive and competitive phase.

The results and analysis of Test 7 Throwing Dummies 10 times are similar in dynamics to Rollover in Wrestling bridge 10 times (Test 3 ) and $30 \mathrm{~m}$ Sprint Running (Test 5).

\section{DISCUSSION}

The results show that the experimentation of our work program for the improvement and preservation of speed-strength endurance significantly improved general and specific events motor (physical) characteristics of the athletes and their technical and tactical skills of hence the improvement of sports performance.

It is considering that by applying a specialized methodology with our block periodization program greatly improved the basic motor skills of speed and explosive power and optimaly performance in the most important competition of the year that prepares the wrestlers to peak at the right time such as National Championship, European Championships and World Championships.

In conclusion it is necessary to continue the researches on the specific problems of the planning of the 
strength and conditioning program training in the field of wrestling methodology. Periodically surveys of anthropometric performance, basic motor skills as well as technical-tactical skills need to be made, identifying the interrelationships between them, which would allow the process of training impacts to focus on those indicators that determine the effectiveness of the training and in the competitive conditions.

\section{REFERECES}

Bagayev, S. (1998). Modern tendencies in the structure of means of technical-tactical actions in free style wrestling and methods of improvement. Diss., M., pp. 23 Igumenov, M., Akopyan, O., Mamiashvili, N., and Osotov, V. (1998). Methodology of speed-force training of wrestlers. Topical problems of sports wrestling. - M.: RGAFK, pp. 58 - 60

Iliev, I. (2015). Methodology of preparation in female wrestling Dis., pp. 22-26
Matveev, L. (1977). Fundamentals of sports training, M., 1977

Petrov, R. (1978). Improvement of the technical and tactical skill of the wrestlers, MIF

Stanchev, N. (2015). Physical Training of the wrestlers, Sports \& Science, NSA Press

Shakhmuradov,A., Sukhanov,D. (1998). Programming of means and methods of training effects in martial arts. Physical Education, Education and Science, pp. 58 - 59

Alexander, L. (2010). Weekly Preparation Rrogramme for Elite Wrestlers.

Baechle, T., Earle, R. (2008). Essentials of Strength Training and Conditioning, Third edition, pp. 508.

Corresponding author: Iliya Iliev, PhD

Department "Wrestling and Judo" National Sports Academy "Vassil Levski" Studentski grad, Sofia 1700, Bulgaria E-mail: ilioiliev@abv.bg 